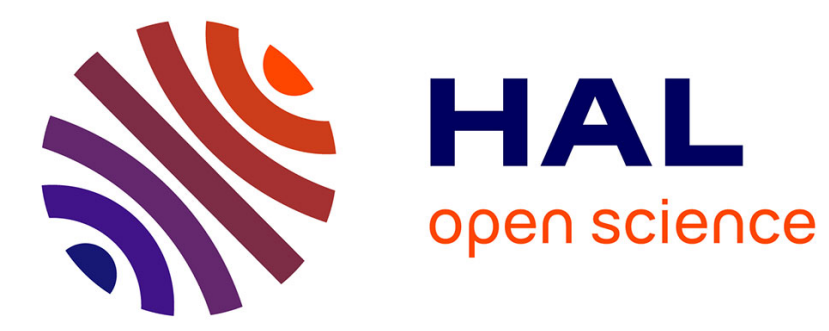

\title{
infections in a general hospital: characteristics and outcomes
}

\author{
G. Samonis, E. K. Vouloumanou, M. Christofaki, D. Dimopoulou, S. Maraki, \\ E. Triantafyllou, D. P. Kofteridis, M. E. Falagas
}

\section{- To cite this version:}

G. Samonis, E. K. Vouloumanou, M. Christofaki, D. Dimopoulou, S. Maraki, et al.. infections in a general hospital: characteristics and outcomes. European Journal of Clinical Microbiology and Infectious Diseases, 2011, 30 (5), pp.653-660. 10.1007/s10096-010-1135-4 . hal-00658170

\section{HAL Id: hal-00658170 https://hal.science/hal-00658170}

Submitted on 10 Jan 2012

HAL is a multi-disciplinary open access archive for the deposit and dissemination of scientific research documents, whether they are published or not. The documents may come from teaching and research institutions in France or abroad, or from public or private research centers.
L'archive ouverte pluridisciplinaire HAL, est destinée au dépôt et à la diffusion de documents scientifiques de niveau recherche, publiés ou non, émanant des établissements d'enseignement et de recherche français ou étrangers, des laboratoires publics ou privés. 
$1 \quad$ Serratia infections in a general hospital: characteristics and outcomes

3 George Samonis, MD, PhD, ${ }^{1}$ Evridiki K. Vouloumanou, MD, ${ }^{2}$ Maria Christofaki, MD, ${ }^{1}$

7 1. Department of Internal Medicine, University Hospital of Heraklion, Heraklion, Crete, 8 Greece

9 2. Alfa Institute of Biomedical Sciences (AIBS), Athens, Greece

10 3. Department of Clinical Microbiology, University Hospital of Heraklion, Heraklion,

11 Crete, Greece

12 4. National Technical University of Athens, Athens, Greece

13 5. Department of Medicine, Henry Dunant Hospital, Athens, Greece

14 6. Department of Medicine, Tufts University School of Medicine, Boston,

15 Massachusetts, USA

Corresponding author: Matthew E. Falagas, MD, MSc, DSc

Alfa Institute of Biomedical Sciences (AIBS), 9 Neapoleos Street, 15123 Marousi, Athens, Greece

E-mail: m.falagas@aibs.gr

24 Running title: Serratia infections in a general hospital

25 Conflict of interest: None

26 Funding: None

27 Word count: abstract: 199, text: $\underline{2393}$

28 Number of tables: 3

29 Number of references: 52 


\section{Abstract}

32 Objective We aimed to present our experience regarding infections caused by Serratia 33 spp. in a region with relatively high antimicrobial resistance rates.

34 Methods We retrospectively reviewed the databases of the microbiological laboratory

35 of the University hospital of Heraklion, Crete (2/2004-12/2009).

36 Results A total of 77 patients $[67.5 \%$ men, mean age \pm standard deviation (SD)=

$3756.9 \pm 24.5$ years) were identified; $37.7 \%$ were outpatients. Sixty-five (84.4\%) of the 77

38 included patients had a Serratia marcescens isolate; the remaining 12 patients had a

39 non-marcescens Serratia spp. The most frequently observed infections were respiratory

40 tract infection (32.5\%) and keratitis/endophthalmitis (20.8\%). Seventy-three (94.9\%)

41 patients were cured. Four deaths were observed; 3 of them were considered as attributed

42 to the Serratia infection. No difference was found regarding the characteristics and

43 outcomes between patients with Serratia marcescens and non-marcescens infections. In

44 addition, antipseudomonal penicillins, as well as their combinations with beta-lactamase

45 inhibitors, carbapenems, and fluoroquinolones exhibited high antimicrobial activity

46 against both the tested Serratia marcescens and non-marcescens isolates.

47 Conclusion Our study adds useful information regarding the characteristics and outcomes of patients with Serratia infection, as well as the susceptibilities of the respective Serratia marcescens and non-marcescens isolates, in a region with relatively

50 high levels of antimicrobial resistance.

52 Keywords: Enterobacteriaceae, Serratia liquefaciens, Serratia rubidaea, beta-

53 lactamase, nosocomial infection 
56 Serratia spp, particularly Serratia marcescens, are mainly encountered as causative

57 pathogens of nosocomial infections and nosocomial outbreaks. ${ }^{1,2}$ Specifically, Serratia

58 spp. are incriminated for outbreaks in neonatal intensive care units (NICUs). ${ }^{3-5}$ In addition, due to their ability of biofilm formation and the production of enzymes including gelatinase, elastase and alkaline protease, Serratia spp. manage to invade human corneal epithelial cells and cause keratitis, and particularly contact lens-related keratitis. 6,7

63

64 Even though Serratia spp. are mainly considered nosocomial pathogens, recently published population-based studies suggested that a considerable percentage of the identified Serratia infections is community-acquired. ${ }^{6,8}$ Even though Serratia marcescens accounts for the majority of the identified Serratia isolates, many reports regarding infections and outbreaks caused from Serratia spp. other than Serratia marcescens, also appeared in the literature. ${ }^{7,9-12}$ In addition, another issue that intensified the importance of Serratia infections is the emergence of multi-drug resistant Serratia isolates, and particularly extended spectrum beta-lactamase producing Serratia isolates (ESBLs). ${ }^{13-15}$

In this regard, the aim of our study was to present our experience regarding the characteristics and outcomes of patients with infections caused from Serratia spp. at a university hospital of a region with relatively high levels of antimicrobial resistance. ${ }^{16-20}$

\section{Methods}

\section{Study design and patient population}

We present a descriptive study, based on the retrospective evaluation of a case series.

81 Specifically, we retrospectively reviewed the databases of the microbiological

82 laboratory of the University hospital of Heraklion, Crete in order to identify patients

83 from whom Serratia spp. were isolated, during a 5-year period (February 2004-

84 December 2009). The University hospital of Heraklion, Crete, is a 650-bed tertiary care centre, serving a population of approximately 650.000 individuals, with approximately 65.000-70.000 admitted patients/year. The following data were retrieved from the available medical records of the respective patients: sex, age, department of hospitalization, potential risk factors for acquisition of nosocomial infections (including 
presence of a urinary catheter), type of Serratia infection, antibiotic treatment administered for the infection, duration of hospitalization, as well as the outcome of the infection.

With regard to the evaluated potential risk factors in particular, the objective criteria of malnutrition were a $\mathrm{BMI}<18.5$, or unintentional weight loss of more than $5 \%$ in the last month, or more than $10 \%$ in the last 6 months, whereas trauma was defined as any injury or wound infection. When more than one Serratia isolates were identified from a patient, we selected the $1^{\text {st }}$ isolate for inclusion in our study. Moreover, we retrieved data regarding any other pathogens were simultaneously identified from the same clinical specimen.

\section{Microbiological testing}

The identification of the isolates was performed with the use of standard biochemical methods, the API 20 E system and the Vitek2 automated system (BioMérieux, Marcy l' Etoile, France). ${ }^{21}$ The antimicrobial susceptibility of the tested isolates to the evaluated antibiotic agents was determined by using the Vitek2 system and the results were interpreted according to CLSI criteria. ${ }^{22}$

\section{Statistical analysis}

We performed comparisons regarding demographic and clinical characteristics between the included patients with a clinical specimen that yielded a Serratia marcescens isolate and those with a clinical specimen that yielded a Serratia spp. isolate (other than Serratia marcescens). The $\chi^{2}$ test or the Fisher exact tests were used, when appropriate, in the comparisons regarding categorical variables, whereas the t-test was used in the comparisons regarding continuous variables. For non-normally distributed continuous variables, the Mann-Whitney signed-rank test was used. A p value of $<0.05$ was regarded as indicative of statistical significance. The comparisons were performed with the use of the OpenEpi Software, ${ }^{23}$ and the SPSS software version 13.0 (SPPS Inc, Chicago, Illinois, USA).

\section{Results}

\section{Patient characteristics}

A total of 77 patients were identified as having a clinical specimen that yielded a Serratia spp. isolate during the study period. Detailed data regarding the demographic 
and clinical characteristics of the included patients are presented in Table 1.

126 Specifically, the mean age \pm standard deviation (SD) of the included patients was

$12756.9 \pm 24.5$ years. Two of the 77 included patients were infants ( 7 and 8 months,

128 respectively). The majority $(67.5 \%)$ of the included patients were men. Regarding the

129 department of hospitalization, the majority (59.7\%) of the included patients were

130 admitted in medical wards, whereas a percentage of $37.7 \%$ were outpatients. Seventeen

131 (22.1\%) of the 77 included patients did not have any comorbidity. Regarding the

132 remaining 60 patients, cardiac diseases were reported most frequently (42.9\%). A

133 percentage of $32.5 \%$ of the included patients were immunosuppressed, $24.7 \%$ were

134 treated with corticosteroids, $19.5 \%$ had undergone surgery, $13 \%$ had a urinary catheter,

$1359.1 \%$ were trauma-patients, and $7.8 \%$ were malnourished. In addition, 10 of the

136 evaluated patients were admitted in the ICU; 2 of them on mechanical ventilation. No

137 patient had a central venous catheter.

138

139 Infections and outcomes

140 A percentage of $32.5 \%$ of the included patients had a respiratory tract infection,

141 followed by a $20.8 \%$ that had keratitis/endophthalmitis. None of the latter ocular

142 infections was hospital-acquired. Other types of infections observed were skin and soft

143 tissue infections (16.9\%), urinary tract infections (13.0\%), sepsis (6.5\%), and

144 cholecystitis (3.9\%). In addition, $8(10.4 \%)$ of the included patients were considered as

145 colonized with Serratia spp. With regard to the patients' outcomes, 73 (94.9\%) of the

14677 included patients were cured. Four deaths were observed during hospitalization in

147 our case series. Three of the 4 deceased patients had monomicrobial Serratia infections,

148 whereas the remaining 1 patient had also an infection due to Citrobacter freundii. The 4

149 deaths were evaluated by the clinicians that took care of the specific patients as well as

150 the study investigators. Three of these 4 deaths were considered as occurring due to the

151 Serratia infection and 1 to other causes.

153 Comparisons regarding patient subpopulations

154 Comparative data regarding the included patients providing a clinical specimen that

155 yielded a Serratia marcescens isolate and those with a clinical specimen that yielded a

156 Serratia spp. isolate (other than Serratia marcescens) are also presented in Table 1. No

157 difference was found between the compared patient sub-populations regarding the

158 analyzed characteristics and outcomes. 
160 Microbiological characteristics

161 Types of isolates and sites of isolation

162 In Table 2 we present data regarding the isolated Serratia spp, the respective sites of

163 isolation, as well as any other simultaneously isolated non-Serratia species.

164 Specifically, 65 (84.4\%) of the 77 included patients had a Serratia marcescens isolate,

165 whereas the remaining 12 patients had a non-marcescens Serratia spp. These were:

166 Serratia liquefaciens in 5 patients; Serratia rubidaea: 3; Serratia fonticola: 2; Serratia

167 plymuthica: 1 and Serratia ficaria: 1 patient. Detailed data regarding the respective sites

168 of isolation are presented in Table 2. Other isolates, including P. aeruginosa, $K$.

169 pneumoniae, and Candida spp., were identified concurrently to the isolation of the

170 Serratia spp. Detailed data regarding the distribution of the concurrently isolated

171 species are also presented in Table 2.

172

\section{Antimicrobial susceptibility of the tested isolates}

174 The susceptibility rates of the isolated Serratia spp. to the 30 analyzed antimicrobial

175 agents are presented in Table 3. Regarding the isolated Serratia marcescens, that

176 constituted the majority [65/77 (84.4\%)] of the identified Serratia isolates, the

177 following antibiotic agents exhibited substantial antimicrobial activity against the tested

178 isolates (72\%-100\% of the tested isolates were found susceptible): antipseudomonal

179 penicillins (specifically, ticarcillin, piperacillin, and ceftazidime), ticarcillin-clavulanic

180 acid, piperacillin-tazobactam, $3^{\text {rd }}$ generation cephalosporins (cefotaxime and

181 ceftriaxone), carbapenems (imipenem and meropenem), aztreonam, tobramycin,

182 netilmicin, nitofurantoin, and quinolones (specifically, pefloxacin, ofloxacin,

183 norfloxacin, and ciprofloxacin).

185 Regarding the 12 tested non-marcescens Serratia spp., all of them were found

186 susceptible to the following antimicrobial agents: ticarcillin, piperacillin, ticarcillin-

187 clavulanic acid, piperacillin-tazobactam, ceftazidime, ceftriaxone, cefotaxime,

188 imipenem, meropenem, aztreonam, tobramycin, netilmicin, nitrofurantoin, pefloxacin,

189 ofloxacin, norfloxacin, and ciprofloxacin. In addition, amikacin, gentamicin, and

190 chloramphenicol exhibited substantial antimicrobial activity against the 12 tested

191 isolates $(83.3 \%$ each).

192

193 Discussion 
194 A total of 77 patients providing a clinical specimen that yielded a Serratia spp. isolate,

195 were identified in a 700-bed tertiary care hospital during a 5-year period. The majority

196 of the Serratia isolates were identified in male patients. This observation is in

197 accordance with the findings of recent population-based studies, in which males were

198 considered to be at higher risk for the acquisition of a Serratia isolate. ${ }^{8}$ In addition, ICU

199 patients were represented by rather low percentages (13\%) in this cohort, whereas a

200 considerable percentage (38\%) of the included patients were outpatients. Indeed,

201 population-based studies also reported that the majority of the isolated Serratia species, ${ }^{8}$

202 including a considerable percentage of Serratia bacteremic episodes were of community

203 onset. $^{24}$

205 With regard to the observed Serratia infections, these were mostly respiratory tract

206 infections, followed by ocular infections, including keratitis and/or endophthalmitis,

207 skin and soft tissue infections, and urinary tract infections. Indeed, due to their ability

208 for biofilm formation, based on the interaction of quorum sensing system and nutrient

209 factors, ${ }^{25,26}$ Serratia spp frequently colonize medical devices, such as bronchoscopes, ${ }^{27}$

210 urinary catheters, ${ }^{28}$ water supplies, ${ }^{29}$ whereas long-term carriage in the hands of

211 healthcare workers has been reported, as well. ${ }^{30}$ Consequently, Serratia spp are

212 frequently incriminated for hospital-acquired bacteremias nosocomial respiratory and

213 urinary tract infections, and nosocomial outbreaks. ${ }^{31-34}$ Specifically, $13 \%$ of the

214 included patients had a urinary catheter. In addition, due to the production of specific

215 enzymes such as gelatinase, elastase and alkaline protease, Serratia spp. cause ocular

216 infections including ulcerative keratitis, particularly contact lens-related keratitis, 6, 35

217 and endophthalmitis. ${ }^{36,37}$ Moreover, immunocompromised patients are considered more

218 prone to Serratia infections. Of note, a considerable percentage of $32.5 \%$ of the

219 included patients were immunosuppressed, and an additional $24.7 \%$ received

220 corticosteroids.

222 Serratia marcescens is the most frequently isolated Serratia spp. However, other

223 Serratia spp. including Serratia liquefaciens, Serratia plymuthica, and Serratia

224 rubidaea, are recently identified as the cause of Serratia nosocomial infections and

225 outbreaks. ${ }^{10,12,38,39}$ Furthermore, non-marcescens Serratia spp are also incriminated for

226 community-acquired infections. ${ }^{40}$ A possible explanation that has been proposed for the

227 relative scarcity of published evidence regarding non-marcescens Serratia spp.

228 compared to Serratia marcescens is the misidentification of these specific strains by 
commercially available identification systems. ${ }^{41}$ In our study, $12(15.5 \%)$ of the 77

230 included patients provided a clinical specimen that non-marcescens Serratia spp

231 (specifically, Serratia liquefaciens, Serratia rubidaea, Serratia fonticola, Serratia

232 plymuthica, and Serratia ficaria). The majority of the respective infections were

233 respiratory tract infections. Its worth to note that in the comparisons between the patient

234 subpopulations with S. marcescens infection and those with non-marcescens Serratia

235 infection, no difference was found regarding the demographical characteristics,

236 comorbidity, risk-factors, types of infections, as well as infection outcomes.

237

238 As far as mortality is concerned, 4 of the 77 included patients died. Three of these 4

239 deaths were considered to have been probably attributed to the Serratia infection, after a

240 meticulous evaluation of the respective clinical data from the clinicians as well as the

241 study investigators. Regarding mortality from Serratia infections, published evidence

242 report percentages of 5\% and 37\% for Serratia bacteremia 7-day and 6-months

243 mortality, respectively. ${ }^{24}$ However, mortality can occur even in less severe Serratia

244 infections, such as urinary tract infections. Specifically, female gender and the

245 development of secondary S. marcescens bacteremia have been identified as risk factors

246 independently associated with fatality in patients with urinary tract infection due to $S$.

247 marcescens. ${ }^{42}$ Moreover, the emergence of ESBL-producing Serratia spp. intensifies

248 the importance of the issue of Serratia infection-related mortality. Specifically, a 30-day

249 mortality rate of $33 \%$ has been reported for nosocomial patients with ESBL-producing

250 S. marcescens infections. ${ }^{43}$

251

252 Serratia spp. exhibit considerable antimicrobial resistance to penicillins and

253 cephalosporins. This is mainly attributed to the fact that AmpC beta-lactamases are

254 encoded in the chromosome of Serratia spp. The expression of these genes is inducible

255 in most cases. ${ }^{44,45}$ In our study all the 65 tested Serratia marcescens isolates were found

256 resistant to amoxicillin and amoxicillin/clavulanic acid. Similarly, 1 of the 12 non-

257 marcescens Serratia spp was susceptible to the above drugs. This observation was

258 consistent regarding cefalothin, a $1^{\text {st }}$ generation cephalosporin, whereas regarding

259 cefuroxime, lower susceptibility rates were observed for the tested Serratia marcescens

260 compared to the non-marcescens isolates. Additionally, a 35\% of the tested Serratia

261 marcescens isolates and a 50\% of the non-marcescens isolates were found susceptible to

262 cefoxitin. Finally, $3^{\text {rd }}$ generation cephalosporins (ceftazidime and cefotaxime) and 
ceftriaxone exhibited high susceptibility rates regarding the Serratia marcescens and non-marcescens tested isolates (95.4\% and 100\%, respectively).

266 On the other, other beta-lactamases, including CTX-M3, IMP-type, as well as TEM-

267 type have also been identified in Serratia spp. ${ }^{14,46-48}$ Specifically, the issue of the emergence of carbapenem resistance Serratia strains is of major importance. In our study, both imipenem and meropenem exhibited high antimicrobial activity rates against the tested Serratia marcescens and non-marcescens isolates. In addition, among the evaluated antimicrobial agents, tobramycin, netilmicin, nitrofurantoin, as well as the combination of trimethoprim with sulfonamides were also found highly active against the tested Serratia marcescens and non-marcescens isolates. On the contrary, amikacin and gentamicin were found to be more active against the tested non-marcescens isolates (83\%) compared to the tested Serratia marcescens isolates. Finally, fluoroquinolones were also highly active against the tested Serratia marcescens and non-marcescens isolates. However, evidence regarding the chromosome-encoded resistance to fluoroquinolones of Serratia marcescens has appeared in the literature. ${ }^{49-51}$

280 Our study has specific limitations that should be considered. Firstly, one should bear in mind the intrinsic methodological limitations of retrospective cohort studies before the extrapolation of the study findings. In addition, our findings derive from the evaluation of the clinical and microbiological data of a rather limited number of 77 patients that provided a clinical specimen that yielded a Serratia spp. isolate. Moreover, since Serratia spp. are often incriminated for nosocomial epidemics, one may consider that the Serratia strains included in this study are epidemic strains. Yet, even though genetic identification techniques were not used in this study, the 5-year study period is rather contradictory to the potential of a concurrent nosocomial epidemic. However, one may consider that a proportion of the tested Serratia isolates might have been of the same clonal origin. Finally, even though the emergence of ESBL-producing Serratia spp. appears to be an issue of increasing importance, microbiological methods for the identification of ESBL-producing isolates, among the evaluated Serratia isolates, were also not implemented in this study.

In conclusion, our study aids in the clarification of issues regarding the characteristics and outcomes of patients with Serratia infections, as well as regarding the susceptibility patterns of the respective isolates. In the era of alarmingly high antimicrobial resistance, 
and particularly in the era of ESBL-producing enterobacteriaceae, ${ }^{52}$ our findings may provide useful information regarding the infections caused from this specific pathogen,

300 as they derive from a clinical setting with relatively high levels of antimicrobial

301 resistance.

302

\section{Reference list}

304 1. Chemaly RF, Rathod DB, Raad, II. A tertiary care cancer center experience of the

3052007 outbreak of Serratia marcescens bloodstream infection due to prefilled syringes.

306 Infect Control Hosp Epidemiol 2009;30:1237-8.

307 2. Kim JH, Choi WH, Yun SW, Chae SA, Yoo BH. An Outbreak of Serratia marcescens

308 Sepsis in a Pediatric Ward. Clin Pediatr (Phila) 2010.

309 3.Arslan U, Erayman I, Kirdar S, et al. Serratia marcescens sepsis outbreak in a neonatal 310 intensive care unit. Pediatr Int 2010;52:208-12.

311 4.Dessi A, Puddu M, Testa M, Marcialis MA, Pintus MC, Fanos V. Serratia marcescens

312 infections and outbreaks in neonatal intensive care units. J Chemother 2009;21:493-9.

313 5. Voelz A, Muller A, Gillen J, et al. Outbreaks of Serratia marcescens in neonatal and

314 pediatric intensive care units: clinical aspects, risk factors and management. Int J Hyg

315 Environ Health 2010;213:79-87.

316 6. Pinna A, Usai D, Sechi LA, Carta A, Zanetti S. Detection of virulence factors in

317 Serratia strains isolated from contact lens-associated corneal ulcers. Acta Ophthalmol 3182009.

319 7. Szczotka-Flynn LB, Imamura Y, Chandra J, et al. Increased resistance of contact

320 lens-related bacterial biofilms to antimicrobial activity of soft contact lens care

321 solutions. Cornea 2009;28:918-26.

322 8. Laupland KB, Parkins MD, Gregson DB, Church DL, Ross T, Pitout JD. Population-

323 based laboratory surveillance for Serratia species isolates in a large Canadian health

324 region. Eur J Clin Microbiol Infect Dis 2008;27:89-95.

325 9. Dalamaga M, Pantelaki M, Karmaniolas K, Matekovits A, Daskalopoulou K.

326 Cutaneous abscess and bacteremia due to Serratia ficaria. J Eur Acad Dermatol

327 Venereol 2008;22:1388-9.

328 10. Dubouix A, Roques C, Segonds C, et al. Epidemiological investigation of a Serratia

329 liquefaciens outbreak in a neurosurgery department. J Hosp Infect 2005;60:8-13.

330 11. Grohskopf LA, Roth VR, Feikin DR, et al. Serratia liquefaciens bloodstream

331 infections from contamination of epoetin alfa at a hemodialysis center. N Engl J Med

332 2001;344:1491-7. 
334 pseudarthrosis caused by Serratia plymuthica. Joint Bone Spine 2008;75:506-7.

335 13. Crivaro V, Bagattini M, Salza MF, et al. Risk factors for extended-spectrum beta336 lactamase-producing Serratia marcescens and Klebsiella pneumoniae acquisition in a neonatal intensive care unit. J Hosp Infect 2007;67:135-41. 14. Mlynarczyk A, Szymanek K, Sawicka-Grzelak A, et al. CTX-M and TEM as predominant types of extended spectrum beta-lactamases among Serratia marcescens isolated from solid organ recipients. Transplant Proc 2009;41:3253-5. 15. Rizvi M, Fatima N, Shukla I, Malik A. Epidemiology of extended spectrum betalactamases in Serratia and Citrobacter species in North India. Indian J Pathol Microbiol 2010;53:193-4.

344 16. Falagas ME, Maraki S, Karageorgopoulos DE, Kastoris AC, Kapaskelis A, Samonis

345 G. Antimicrobial susceptibility of Gram-positive non-urinary isolates to fosfomycin. Int 346 J Antimicrob Agents 2010;35:497-9.

347 17. Falagas ME, Maraki S, Karageorgopoulos DE, Kastoris AC, Mavromanolakis E,

348 Samonis G. Antimicrobial susceptibility of multidrug-resistant (MDR) and extensively

349 drug-resistant (XDR) Enterobacteriaceae isolates to fosfomycin. Int J Antimicrob

350 Agents 2010;35:240-3.

351 18. Maraki S, Samonis G, Rafailidis PI, Vouloumanou EK, Mavromanolakis E, Falagas

352 ME. Susceptibility of urinary tract bacteria to fosfomycin. Antimicrob Agents

353 Chemother 2009;53:4508-10.

354 19. Samonis G, Maraki S, Rafailidis PI, Kapaskelis A, Kastoris AC, Falagas ME.

355 Antimicrobial susceptibility of Gram-negative nonurinary bacteria to fosfomycin and 356 other antimicrobials. Future Microbiol 2010;5:961-70.

357 20. Samonis G, Matthaiou DK, Kofteridis D, Maraki S, Falagas ME. In vitro 358 susceptibility to various antibiotics of colistin-resistant gram-negative bacterial isolates 359 in a general tertiary hospital in Crete, Greece. Clin Infect Dis 2010;50:1689-91.

360 21. Farmer III, JJ, Boatwright KD, Janda JM. Enterobacteriaceae: Introduction and 361 identification. In: Murray P, Baron EJ, Jorgensen JH, Landry ML, Pfaller MA, editors.

362 Manual of clinical microbiology, Ninth ed., Volume 1. Washington: American Society 363 for Microbiology; 2007. p. 649-669. .

364 22. Clinical and Laboratory Standards Institute. Performance standards for antimicrobial 365 susceptibility testing; Nineteenth informational supplement. CLSI Document M100366 S19. Wayne, PA, USA; 2009. 

for Public Health, Version 2.2.1. Updated 2008/04/06 [cited 2008/09/18]; Available

369 from: www.OpenEpi.com.

370 24. Engel HJ, Collignon PJ, Whiting PT, Kennedy KJ. Serratia sp. bacteremia in

371 Canberra, Australia: a population-based study over 10 years. Eur J Clin Microbiol Infect

372 Dis 2009;28:821-4.

373 25. Rice SA, Koh KS, Queck SY, Labbate M, Lam KW, Kjelleberg S. Biofilm

374 formation and sloughing in Serratia marcescens are controlled by quorum sensing and

375 nutrient cues. J Bacteriol 2005;187:3477-85.

376 26. Van Houdt R, Givskov M, Michiels CW. Quorum sensing in Serratia. FEMS

377 Microbiol Rev 2007;31:407-24.

378 27. Molina-Cabrillana J, Rodriguez-Bermejo JC, del Rosario-Quintana C, Bolanos-

379 Rivero M. [Rapid detection of an outbreak of bronchoscopy-associated colonization by

380 Serratia marcescens]. Enferm Infecc Microbiol Clin 2007;25:222-4.

381 28. Jones GL, Muller CT, O'Reilly M, Stickler DJ. Effect of triclosan on the

382 development of bacterial biofilms by urinary tract pathogens on urinary catheters. J

383 Antimicrob Chemother 2006;57:266-72.

384 29. Horcajada JP, Martinez JA, Alcon A, et al. Acquisition of multidrug-resistant

385 Serratia marcescens by critically ill patients who consumed tap water during receipt of

386 oral medication. Infect Control Hosp Epidemiol 2006;27:774-7.

387 30. de Vries JJ, Baas WH, van der Ploeg K, Heesink A, Degener JE, Arends JP.

388 Outbreak of Serratia marcescens colonization and infection traced to a healthcare

389 worker with long-term carriage on the hands. Infect Control Hosp Epidemiol

$390 \quad 2006 ; 27: 1153-8$.

391 31. Casolari C, Pecorari M, Fabio G, et al. A simultaneous outbreak of Serratia

392 marcescens and Klebsiella pneumoniae in a neonatal intensive care unit. J Hosp Infect

393 2005;61:312-20.

394 32.Johnson JS, Croall J, Power JS, Armstrong GR. Fatal Serratia marcescens meningitis

395 and myocarditis in a patient with an indwelling urinary catheter. J Clin Pathol 396 1998;51:789-90.

397 33. Kim BN, Choi SI, Ryoo NH. Three-year follow-up of an outbreak of Serratia

398 marcescens bacteriuria in a neurosurgical intensive care unit. J Korean Med Sci $399 \quad 2006 ; 21: 973-8$.

400 34. Yu WL, Lin CW, Wang DY. Serratia marcescens bacteremia: clinical features and 401 antimicrobial susceptibilities of the isolates. J Microbiol Immunol Infect 1998;31:171-9. 
35. Parment PA. The role of Serratia marcescens in soft contact lens associated ocular infections. A review. Acta Ophthalmol Scand 1997;75:67-71. 36. Latorre G. Endogenous Serratia marcescens endophthalmitis in a preterm infant. Indian J Pediatr 2008;75:410. 37. Mah-Sadorra JH, Najjar DM, Rapuano CJ, Laibson PR, Cohen EJ. Serratia corneal ulcers: a retrospective clinical study. Cornea 2005;24:793-800. 38. Chuang TY, Chuang CP, Cheng HH, Hsueh PR. Aortic valve infective endocarditis caused by Serratia liquefaciens. J Infect 2007;54:e161-3. 39. Sekhsokh Y, Arsalane L, El Ouenass M, Doublali T, Bajjou T, Lahlou Amine I. [Serratia rubidaea bacteremia]. Med Mal Infect 2007;37:287-9.

40. Okada T, Yokota E, Matsumoto I. [Community acquired sepsis by Serratia rubidaea]. Kansenshogaku Zasshi 2002;76:109-12.

414 41. Anahory T, Darbas H, Ongaro O, Jean-Pierre H, Mion P. Serratia ficaria: a misidentified or unidentified rare cause of human infections in fig tree culture zones. $\mathbf{J}$

416 Clin Microbiol 1998;36:3266-72.

417 42. Liu J-W, Hsu Y-M, Huang Y-F. Independent prognostic factors for fatality in 418 patients with urinary tract infection caused by Serratia marcescens. Infect Control Hosp 419 Epidemiol 2004;25:80-2.

420 43. Cheng K-C, Chuang Y-C, Wu L-T, Huang G-C, Yu W-L. Clinical experiences of 421 the infections caused by extended-spectrum beta-lactamase-producing Serratia 422 marcescens at a medical center in Taiwan. Jpn J Infect Dis 2006;59:147-52.

423 44. Park YJ, Park SY, Oh EJ, et al. Occurrence of extended-spectrum beta-lactamases 424 among chromosomal AmpC-producing Enterobacter cloacae, Citrobacter freundii, and 425 Serratia marcescens in Korea and investigation of screening criteria. Diagn Microbiol 426 Infect Dis 2005;51:265-9.

427 45. Rizvi M, Fatima N, Rashid M, et al. Extended spectrum AmpC and metallo-beta428 lactamases in Serratia and Citrobacter spp. in a disc approximation assay. J Infect Dev 429 Ctries 2009;3:285-94.

430 46. Kumamoto Y, Tsukamoto T, Matsukawa M, et al. [Comparative studies on activities 431 of antimicrobial agents against causative organisms isolated from patients with urinary 432 tract infections (2003). I. Susceptibility distribution]. Jpn J Antibiot 2005;58:518-43.

433 47. Tsou MF, Yu WL, Hung SW, et al. Detection of cefotaxime-resistant CTX-M-3 in 434 clinical isolates of Serratia marcescens. Folia Microbiol (Praha) 2004;49:452-6.

435 48. Zhao WH, Hu ZQ, Chen G, Matsushita K, Fukuchi K, Shimamura T.

436 Characterization of imipenem-resistant Serratia marcescens producing IMP-type and 
437 TEM-type beta-lactamases encoded on a single plasmid. Microbiol Res 2007;162:46-

43852.

439 49. Sheng WH, Chen YC, Wang JT, Chang SC, Luh KT, Hsieh WC. Emerging

440 fluoroquinolone-resistance for common clinically important gram-negative bacteria in

441 Taiwan. Diagn Microbiol Infect Dis 2002;43:141-7.

442 50. Acar JF, O'Brien TF, Goldstein FW, Jones RN. The epidemiology of bacterial

443 resistance to quinolones. Drugs 1993;45 Suppl 3:24-8.

444 51. Velasco C, Rodriguez-Martinez JM, Briales A, Diaz de Alba P, Calvo J, Pascual A.

445 Smaqnr, a new chromosome-encoded quinolone resistance determinant in Serratia

446 marcescens. J Antimicrob Chemother 2010;65:239-42.

447 52. Falagas ME, Karageorgopoulos DE. Extended-spectrum beta-lactamase-producing

448 organisms. J Hosp Infect 2009;73:345-54.

449

450

451

452

453 
Table 1. Baseline characteristics, infections and outcomes of the included patients. Mean $( \pm$ SD) or number $(\%)$

\begin{tabular}{|c|c|c|c|c|}
\hline Number of patients & $n_{1}=77$ & $\begin{array}{c}\text { Serratia } \\
\text { marcescens } \\
(\text { Group A) } \\
\mathbf{n}_{2}=\mathbf{6 5}\end{array}$ & $\begin{array}{c}\text { Other Serratia spp. } \\
\text { (non-marcescens) } \\
\text { (Group B) } \\
\mathbf{n}_{3}=\mathbf{1 2}\end{array}$ & $\begin{array}{c}\text { P value } \\
\text { (Group A vs } \\
\text { Group B) }\end{array}$ \\
\hline \multicolumn{5}{|l|}{ Demographics } \\
\hline Age (years) & $56.9 \pm 24.5$ & $56.3 \pm 24.5$ & $59.9 \pm 25.9$ & 0.7 \\
\hline Sex (male) & $52(67.5)$ & $45(69.2)$ & $7(58.3)$ & 0.7 \\
\hline \multicolumn{5}{|c|}{ Department of hospitalization } \\
\hline Medical & $46(59.7)$ & $38(58.5)$ & $8(66.7)$ & 0.8 \\
\hline Surgical & $13(16.9)$ & $11(16.9)$ & $2(16.7)$ & $>0.9$ \\
\hline Pediatric & $2(2.9)$ & $2(3.1)$ & 0 & $>0.9$ \\
\hline ICU & $10(13.0)$ & $10(15.4)$ & 0 & 0.3 \\
\hline Outpatients & $29(37.7)$ & $25(38.5)$ & $4(33.3)$ & $>0.9$ \\
\hline $\begin{array}{l}\text { Transfer from } \\
\text { another hospital }\end{array}$ & $2(2.9)$ & $2(3.1)$ & $0(0)$ & $>0.9$ \\
\hline \multicolumn{5}{|l|}{ Comorbidity } \\
\hline None & $17(22.1)$ & $13(20.0)$ & $4(33.3)$ & 0.5 \\
\hline Diabetes mellitus & $12(15.6)$ & $9(13.8)$ & $3(25.0)$ & 0.6 \\
\hline Cardiac diseases & $33(42.9)$ & $27(41.5)$ & $6(50.0)$ & 0.8 \\
\hline Pulmonary diseases & $14(18.2)$ & $12(18.5)$ & $2(16.7)$ & $>0.9$ \\
\hline Renal diseases & $7(9.1)$ & $5(7.7)$ & $2(16.7)$ & 0.6 \\
\hline Hepatic diseases & $2(2.6)$ & $2(3.1)$ & 0 & $>0.9$ \\
\hline CNS diseases & $11(14.3)$ & $11(16.9)$ & 0 & 0.3 \\
\hline Orthopedic diseases & $9(11.7)$ & $8(12.3)$ & $1(8.3)$ & $>0.9$ \\
\hline Malignancies & $14(18.2)$ & $11(16.9)$ & $3(25.0)$ & 0.8 \\
\hline Autoimmune diseases & $6(7.8)$ & $4(6.2)$ & $2(16.7)$ & 0.5 \\
\hline Hyperurichaemia & $3(3.9)$ & $2(3.1)$ & $1(8.3)$ & 0.8 \\
\hline Smoking & $11(14.3)$ & $10(15.4)$ & $1(8.3)$ & 0.9 \\
\hline $\begin{array}{l}\text { Bening prostate } \\
\text { hyperplasia }\end{array}$ & $5(6.5)$ & $4(6.2)$ & $1(8.3)$ & $>0.9$ \\
\hline Lipofuscinosis & $1(1.3)$ & $1(1.5)$ & 0 & $>0.9$ \\
\hline \multicolumn{5}{|l|}{ Risk factors } \\
\hline Corticosteroids & $19(24.7)$ & $16(24.6)$ & $3(25.0)$ & $>0.9$ \\
\hline Immunosuppression & $25(32.5)$ & $19(29.2)$ & $6(50.0)$ & 0.3 \\
\hline Malnutrition & $6(7.8)$ & $3(4.6)$ & $3(25.0)$ & 0.1 \\
\hline Urinary catheter & $10(13.0)$ & $8(12.3$ & $2(16.7)$ & $>0.9$ \\
\hline Trauma & $7(9.1)$ & $6(9.3)$ & $1(8.3)$ & $>0.9$ \\
\hline Surgery & $15(19.5)$ & $13(20.0)$ & $2(16.7)$ & $>0.9$ \\
\hline \multicolumn{5}{|l|}{ Type of infection } \\
\hline RTI & $25(32.5)$ & $20(30.8)$ & $5(41.7)$ & 0.7 \\
\hline UTI & $10(13.0)$ & $10(15.4)$ & 0 & 0.3 \\
\hline SSTI & $13(16.9)$ & $9(13.9)$ & $4(33.3)$ & 0.2 \\
\hline $\begin{array}{l}\text { Keratitis/endophthal } \\
\text { mitis }\end{array}$ & $16(20.8)$ & $14(21.5)$ & $2(16.7)$ & $>0.9$ \\
\hline Cholecystitis & $3(3.9)$ & $2(3.1)$ & $1(8.3)$ & 0.8 \\
\hline Sepsis & $5(6.5)$ & $4(6.2)$ & $1(8.3)$ & $>0.9$ \\
\hline Colonization & $8(10.4)$ & $8(12.3)$ & 0 & 0.5 \\
\hline $\begin{array}{l}\text { Time to acquisition } \\
\text { of the } 1^{\text {st }} \text { positive } \\
\text { culture for Serratia } \\
\text { spp. }\end{array}$ & $\begin{array}{l}\text { Median (range) })^{*}: \\
2(0-158)\end{array}$ & $\begin{array}{l}\text { Median (range })^{* *}: \\
2(0-158)\end{array}$ & $\begin{array}{c}\text { Median (range) })^{* * *}: \\
2(0-5)\end{array}$ & 0.4 \\
\hline $\begin{array}{l}\text { Duration of } \\
\text { hospitalization } \\
\text { (days) }\end{array}$ & $\begin{array}{l}\text { Median (range) }{ }^{*}: \\
\quad 6(1-206)\end{array}$ & $\begin{array}{c}\text { Median (range) } \\
7(1-206)\end{array}$ & $\begin{array}{l}\text { Median (range })^{* * * *}: \\
5(1-15)\end{array}$ & 0.3 \\
\hline
\end{tabular}




\section{Outcome}

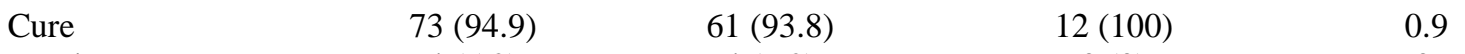

\begin{tabular}{|c|c|}
\hline Death & $4(5.2)$ \\
\hline
\end{tabular}

455Abbreviations: ICU: intensive care unit, CNS: central nervous system, RTI: respiratory tract infection, UTI: 456urinary tract infections, SSTI: skin and soft tissue infection.

457*: NR: $15 / 77(19.2 \%)$

458**: NR: $12 / 65(18.1 \%)$

459***: NR: $3 / 12(25 \%)$

460

461

\section{Table 2. Data regarding the isolated species and sites of isolation.}

Species identified

Serratia spp.

Serratia marcescens $\quad 65(84.4)$

Serratia liquefaciens $\quad 5(6.5)$

Serratia rubidaea 3 (3.9)

Serratia fonticola $2(2.6)$

Serratia plymuthica $1(1.3)$

Serratia ficaria $1(1.3)$

Other species

Staphylococcus spp. $3(3.9)$

Proteus vulgatis $1(1.3)$

Pseudomonas aeruginosa $\quad 4(5.2)$

Klebsiella pneumoniae $\quad 1(1.3)$

Candida spp $2(2.6)$

Escherichia coli $1(1.3)$

Enterococcus faecalis $\quad 1(1.3)$

Mycoplasma pneumoniae $\quad 1(1.3)$

Enterococcus faecalis $\quad 1(1.3)$

Citrobacter freundii $1(1.3)$

Site of isolation

Blood $6(7.8)$

Urine $12(15.6)$

BAL 9 (11.7)

Bronchial secretions $\quad 8(10.4)$

Pharyngeal aspirate $\quad 3$ (3.9)

Nasal aspirate $\quad 1(1.3)$

Sputum $7(9.1)$

Pus $\quad 13(16.8)$

Contact lens $\quad 9(11.7)$

Bile $\quad 3(3.8)$

Ocular aspirate $\quad 6(7.8)$

Conjuctiva $1(1.3)$

Yaloid pus $1(1.3)$

Tracheal tube $1(1.3)$

Number of positive cultures

One $70(90.9)$

Two 7 (9.1)

462 Abbreviations: BAL: bronchoalveolar lavage. 


\begin{tabular}{|c|c|c|c|c|c|c|}
\hline \multirow[t]{2}{*}{ Antimicrobial agents } & \multicolumn{2}{|c|}{$\begin{array}{l}\text { Serratia marcescens } \\
\qquad n_{1}=65\end{array}$} & \multicolumn{2}{|c|}{$\begin{array}{c}\begin{array}{c}\text { Serratia spp. } \\
\text { (non-marcescens) }^{*} \\
\mathbf{n}_{2}=12\end{array} \\
\text { " }\end{array}$} & \multicolumn{2}{|c|}{$\begin{array}{c}\text { All Serratia isolates } \\
\text { tested } \\
n=77\end{array}$} \\
\hline & $\mathbf{S}(\%)$ & I (\%) & $\mathrm{S}(\%)$ & I (\%) & $\mathbf{S}(\%)$ & I (\%) \\
\hline Ampicillin & 0 & 0 & $1(8.3)$ & 0 & $1(1.2)$ & 0 \\
\hline Amoxicillin+Clavulanic acid & 0 & 0 & $1(8.3)$ & 0 & $1(1.2)$ & 0 \\
\hline Ticarcillin & $59(90.8)$ & 0 & $12(100)$ & 0 & $71(92.2)$ & 0 \\
\hline Ticarcillin+Clavulanic acid & $61(93.8)$ & $1(1.5)$ & $12(100)$ & 0 & $73(94.8)$ & $1(1.2)$ \\
\hline Piperacillin & $60(92.3)$ & $2(3.1)$ & $12(100)$ & 0 & $72(96.0)$ & $2(2.5)$ \\
\hline Piperacillin/tazobactam & $62(95.4)$ & 0 & $12(100)$ & 0 & 74 (98.6) & 0 \\
\hline Cefalothin & 0 & 0 & $1(8.3)$ & 0 & $1(1.2)$ & 0 \\
\hline Cefuroxime & $2(3.1)$ & $1(1.5)$ & $3(25.0)$ & 0 & $5(6.4)$ & $1(1.2)$ \\
\hline Cefoxitin & $23(35.4)$ & $29(44.6)$ & $6(50.0)$ & $2(16.7)$ & $30(38.9)$ & $31(40.2)$ \\
\hline Cefotaxime & $62(95.4)$ & 0 & $12(100)$ & 0 & 74 (98.6) & 0 \\
\hline Ceftriaxone & $62(95.4)$ & 0 & $12(100)$ & 0 & 74 (98.6) & 0 \\
\hline Ceftazidime & $62(95.4)$ & 0 & $12(100)$ & 0 & 74 (98.6) & 0 \\
\hline Imipenem & $62(95.4)$ & 0 & $12(100)$ & 0 & 74 (98.6) & 0 \\
\hline Meropenem & 64 (98.4) & 0 & $12(100)$ & 0 & 76 (98.7) & 0 \\
\hline Aztreonam & $65(100)$ & 0 & $12(100)$ & 0 & 77 (100) & 0 \\
\hline Tobramycin & $60(92.3)$ & $2(3.1)$ & $12(100)$ & 0 & $72(93.5)$ & $2(2.5)$ \\
\hline Amikacin & $34(52.3)$ & $5(7.7)$ & $10(83.3)$ & 0 & $44(57.1)$ & $5(6.4)$ \\
\hline Gentamicin & $35(53.8)$ & $4(6.2)$ & $10(83.3)$ & 0 & $45(58.4)$ & $4(5.1)$ \\
\hline Netilmicin & $58(89.2)$ & $2(3.1)$ & $12(100)$ & 0 & $71(92.2)$ & $2(2.5)$ \\
\hline Chloramphenicol & $30 / 61(49.2)^{* *}$ & $5(8.21)$ & $10(83.3)$ & 0 & $40 / 73(54.7)$ & $5 / 73(6.8)$ \\
\hline Tetracycline & $17 / 25(68.0)^{* * *}$ & $3(12.0)$ & $3 / 3^{\#}$ & 0 & $21 / 28(75)$ & $3 / 28(10.7)$ \\
\hline Trimethoprim & $4(6.2)$ & 0 & $1(8.3)$ & 0 & $5(6.4)$ & 0 \\
\hline Trimethoprim+Sulfonamides & $63(96.9)$ & $1(1.5)$ & $12(100)$ & 0 & $75(97.4)$ & $1(1.2)$ \\
\hline Nitrofurantoin & $59(90.7)$ & 0 & $12(100)$ & 0 & $71(92.2)$ & 0 \\
\hline Nalidixic acid & $4(6.2)$ & $1(1.5)$ & $1(8.3)$ & $2(16.7)$ & $5(6.4)$ & $3(3.8)$ \\
\hline Pefloxacin & $60(92.3)$ & 0 & $12(100)$ & 0 & $72(93.5)$ & 0 \\
\hline Ofloxacin & $62(95.4)$ & $1(1.5)$ & $12(100)$ & 0 & $74(96.1)$ & $1(1.2)$ \\
\hline Norfloxacin & $63(96.9)$ & 0 & $12(100)$ & 0 & $75(97.4)$ & 0 \\
\hline Ciprofloxacin & $63(96.9)$ & 0 & $12(100)$ & 0 & $75(97.4)$ & 0 \\
\hline
\end{tabular}

Abbreviations: S: susceptibility, I: intermediate susceptibility, NR: Not Reported.

*: These include: Serratia liquefaciens: 5, Serratia rubidaea: 3, Serratia fonticola: 2, Serratia plymuthica: 1 ,

Serratia ficaria: 1.

**: NR: 4/66 (6.1\%)

***: NR: $40 / 66(60.6 \%)$

\#: NR: $9 / 12(75.0 \%)$ 